\title{
Technè
}

La science au service de l'histoire de l'art et de la préservation des biens culturels

41 | 2015

Arts textiles antiques et modernes. Approche scientifique et restauration

\section{La restauration d'une tapisserie bruxelloise de la Renaissance par traitement enzymatique}

Restoration of a Renaissance Brussels tapestry using an enzymatic treatment

\section{Sylvie Forestier et Agnès Bos}

\section{(2) OpenEdition}

12 Journals

Édition électronique

URL : http://journals.openedition.org/techne/4843

DOI : $10.4000 /$ techne.4843

ISSN : 2534-5168

Éditeur

C2RMF

\section{Édition imprimée}

Date de publication : 25 novembre 2015

Pagination : 101-107

ISBN : 978-2-7118-6248-1

ISSN : 1254-7867

Référence électronique

Sylvie Forestier et Agnès Bos, « La restauration d'une tapisserie bruxelloise de la Renaissance par traitement enzymatique », Technè [En ligne], 41 | 2015, mis en ligne le 08 août 2020, consulté le 11 mars 2021. URL : http://journals.openedition.org/techne/4843 ; DOI : https://doi.org/10.4000/techne. 4843

\section{cc) (1)}

La revue Technè. La science au service de l'histoire de l'art et de la préservation des biens culturels est mise à disposition selon les termes de la Licence Creative Commons Attribution - Pas d'Utilisation Commerciale - Pas de Modification 4.0 International. 
Sylvie Forestier

Agnès Bos

\section{La restauration d'une tapisserie bruxelloise de la Renaissance par traitement enzymatique}

Restoration of a Renaissance Brussels tapestry using an enzymatic treatment
Résumé. Une petite tapisserie bruxelloise du XVI siècle, tissée en laine, soie, et comportant des filés métalliques, appartenant au musée du Louvre, a fait l'objet en 2009-2010 d'une restauration particulière. La pièce, tendue sur un châssis de bois, s'était déformée, les fibres étaient devenues fragiles et cassantes, offrant en outre un aspect jauni et terne. Le revers était en effet couvert d'un épais badigeon de colle qui avait imprégné profondément les fibres. Éliminer cette colle était nécessaire avant d'entreprendre une consolidation des parties fragiles et d'envisager une nouvelle présentation de la tapisserie.

Des essais de traitement avec une enzyme a-amylase ont été entrepris afin d'établir la faisabilité d'un tel traitement et les paramètres appropriés. Le badigeon de colle a été éliminé par immersion de la tapisserie dans une solution tamponnée contenant l'a-amylase. La tapisserie a ensuite pu être consolidée puis doublée afin de pouvoir être de nouveau présentée.

Mots-clés. Tapisserie, XVI siècle, Frans Geubels, enzymes, a-amylase, musée du Louvre.
Abstract. A small 16th-century Brussels tapestry woven in wool, silk and metallic thread, now belonging to the Louvre, underwent a specific restoration process in 2009-10. Stretched over a wooden frame, the tapestry had distorted, while its fibres had become fragile and brittle. Its overall appearance had also yellowed and dulled. The back of the tapestry was in fact coated with a thick layer of glue that had seeped through to the fibres. Removing this glue was necessary before attempting to strengthen the fragile areas and envisage a new manner of presenting the tapestry. Tests were carried out using alpha-amylase to establish the feasibility of such a treatment and the appropriate parameters. The layer of glue was removed by immersing the tapestry in a buffer solution containing the enzyme alpha-amylase. The tapestry could then be strengthened and lined before being put back on display.

Keywords. Tapestry, 16th century, Frans Geubels, enzymes, alpha-amylase, Louvre.
Depuis 1903, le département des Objets d'art du musée du Louvre abrite une tapisserie représentant l'Adoration des Mages (OA 5942), aux dimensions modestes (181 x 143,5 cm), qui avait la particularité d'être tendue sur un châssis en bois, disposition qui semble antérieure à son acquisition par le musée (fig. 1 et 2). Elle avait appartenu au grand collectionneur Frédéric Spitzer avant d'être achetée et léguée au musée du Louvre par Charles Rochard. La pièce, pourtant d'une grande qualité stylistique et d'un tissage fin et avec des filés métalliques, n'avait guère attiré l'attention des spécialistes et ne semble pas avoir été restaurée depuis son entrée dans les collections publiques.

En 2008, à l'occasion d'un prêt à une exposition, il fut décidé de procéder à la restauration de la tapisserie, notamment de la dépose du châssis, afin d'en améliorer les conditions de conservation. Cette présentation était en effet néfaste car elle créait tensions et déformations, et engendrait des altérations des soies dans la partie supérieure, ainsi que des lacunes dans les angles et sur les bords. Des galons modernes y étaient cousus et étaient cloués dans le châssis. Par ailleurs, l'aspect de l'œuvre était terne et jauni. Une toile de lin, fixée sur le cadre, cachait le revers de la tapisserie. L'intervention de restauration consistait a priori, outre cette dépose, en une opération tout à fait habituelle de consolidation et de doublage de la pièce. Mais il en fut autrement.

\section{Après la dépose du châssis}

La dépose du châssis fut à l'origine de deux surprises. La bonne surprise fut de retrouver, sous les galons modernes, les galons originaux, quasi intacts, portant la marque BrabantBruxelles et un monogramme d'atelier identifié comme celui de Frans Geubels, ce qui permet de connaître maintenant avec certitude le lieu de production de cette pièce jusque-là hypothétique et de proposer une datation plus tardive que

Sylvie Forestier, conservateur restaurateur d'œuvres d'art, spécialité textiles (syl-forestier@orange.fr). Agnès Bos, conservateur au département des Objets d'art, musée du Louvre (agnes.bos@louvre.fr). 


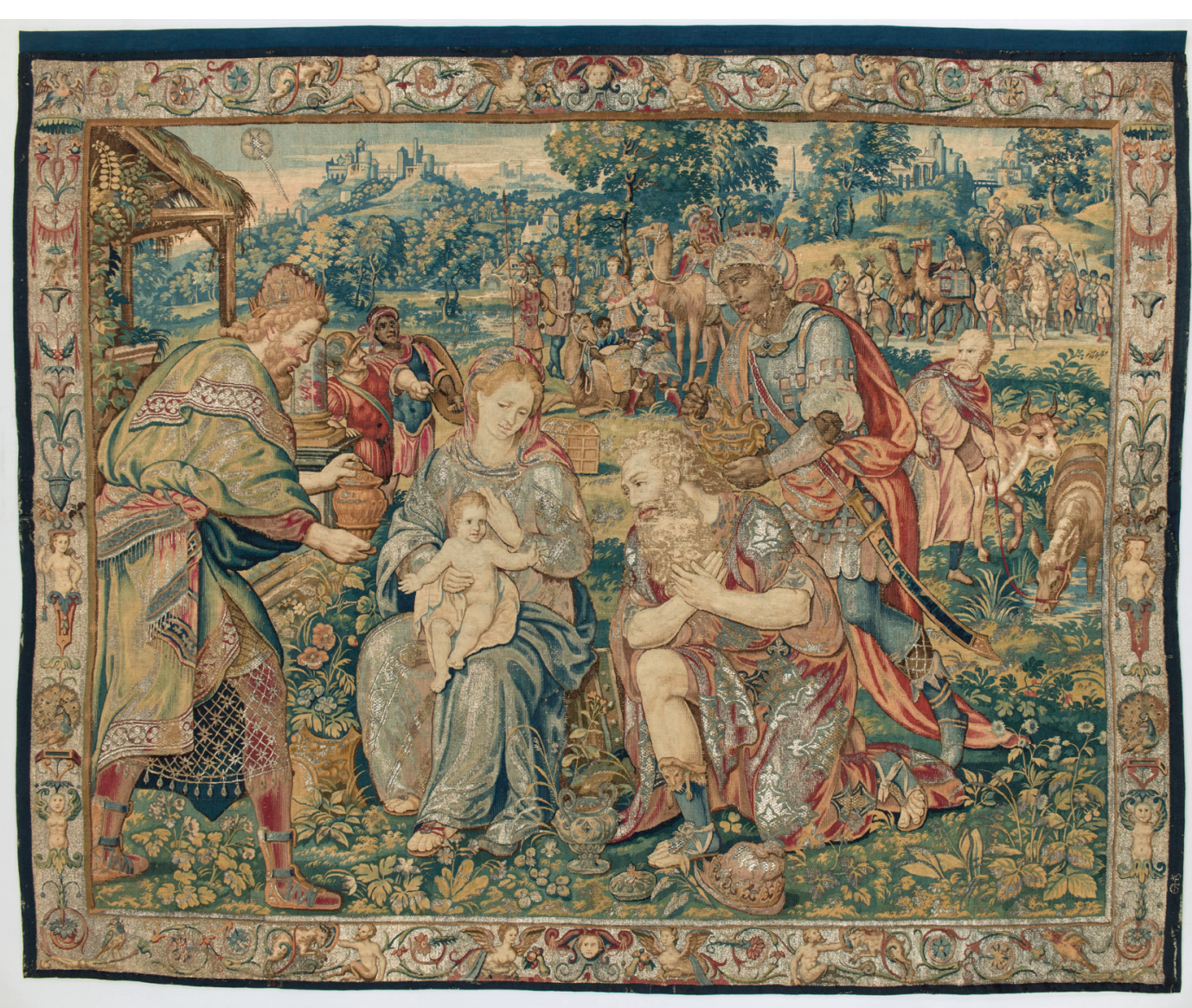

Fig. 1. Atelier de Frans Geubels, Adoration des

Mages, Bruxelles, vers 1570, tapisserie en laine, soie et filés métalliques, 181 x 143,5 cm (après restauration). Paris, musée du Louvre, département des Objets d'art. (C) Musée du Louvre, Dist. RMNGrand Palais/Philippe Fuzeau.

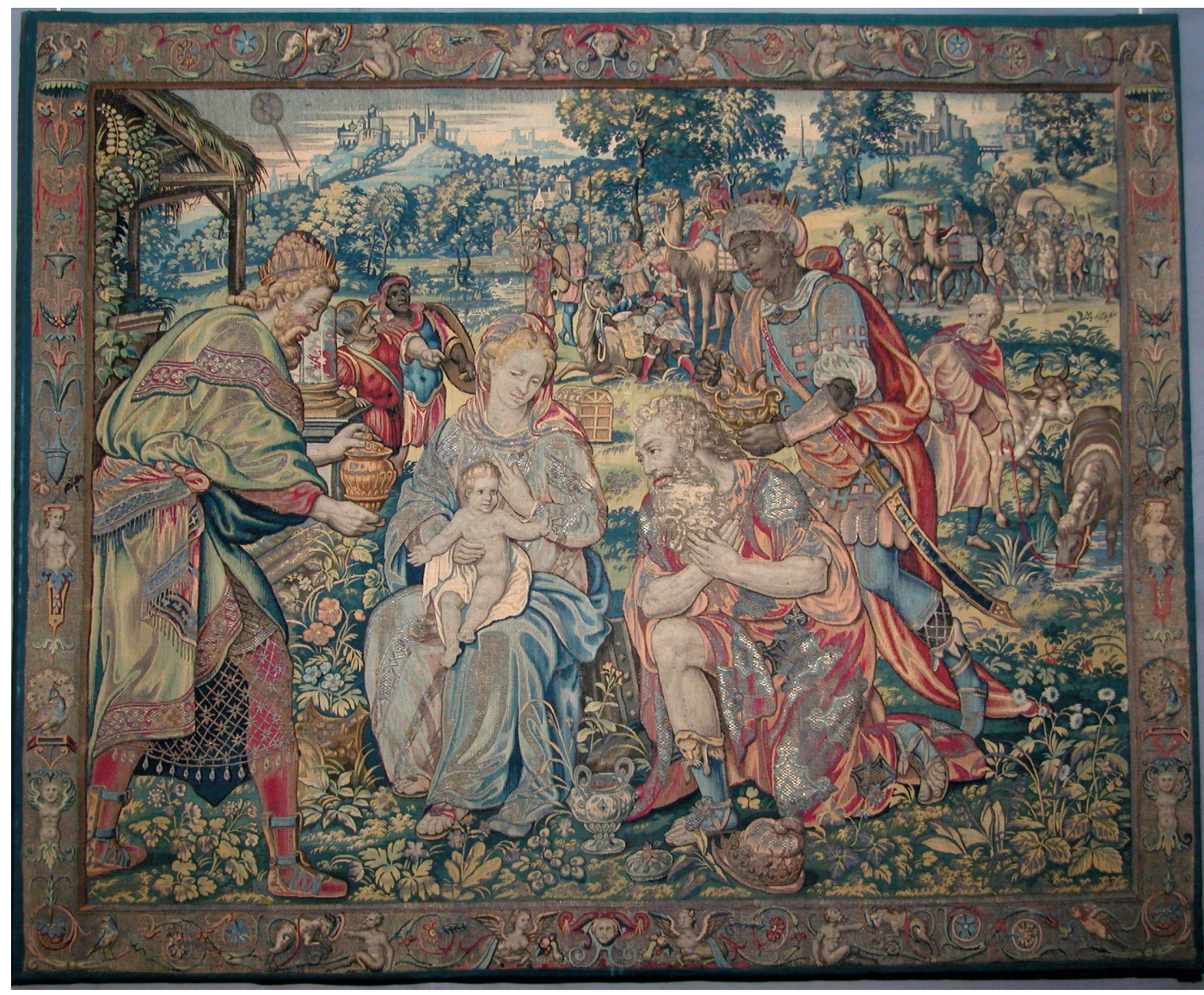

Fig. 2. Tapisserie avant restauration, fixée sur un châssis.

() Sylvie Forestier. 


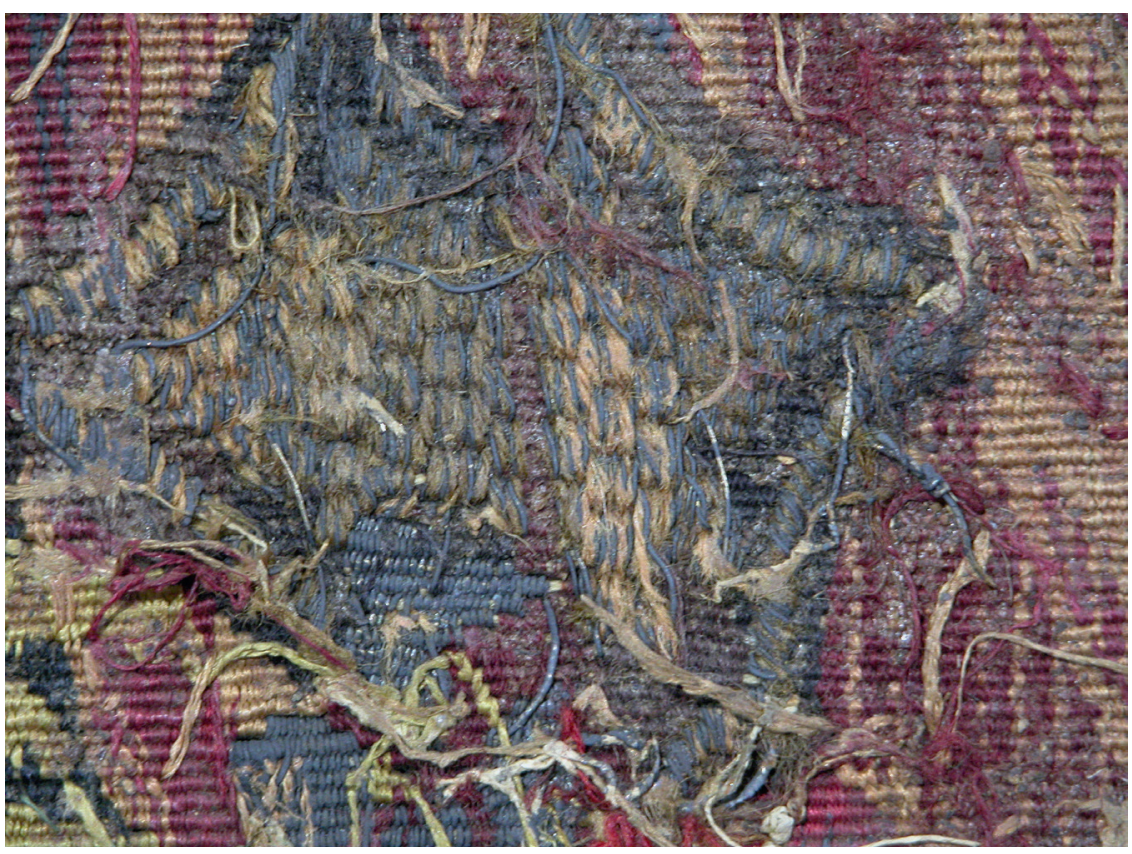

Fig. 3. Tapisserie avant restauration. Détail du revers. (C) Sylvie Forestier.

celle qui était alors avancée. En revanche, l'accès au revers de la tapisserie permit de faire le triste constat qu'il était imprégné d'un badigeon de colle brun. Les trames flottantes du revers étaient emmêlées, engluées, dures et cassantes. La colle avait profondément migré dans les fibres et pénétré entièrement la tapisserie (fig. 3).

Les analyses de la colle, réalisées par Nathalie Balcar au C2RMF, ont identifié un adhésif organique composé de colle d'amidon et de colle protéinique, plus connu sous le nom de colle de pâte ${ }^{1}$. Ce mélange, traditionnellement employé pour le marouflage et l'entoilage des tableaux, fut appliqué à la tapisserie avant qu'elle ne soit ensuite tendue sur châssis. La colle avait durci et s'était oxydée. Elle restait cependant sensible à l'humidité et dégageait des produits acides qui compromettaient la conservation de la tapisserie. Mais on ne pouvait envisager l'élimination de la colle par un simple traitement en milieu aqueux : d'une part, la dissociation brutale des acides dans l'eau pouvait provoquer des dégâts irréversibles sur le textile et, d'autre part, l'amidon, principal composant de la colle de pâte, est insoluble dans l'eau. Sa solubilisation pouvait en revanche s'envisager avec des enzymes.

\section{La mise au point du protocole de traitement enzymatique}

Des traitements enzymatiques sur textiles avaient précédemment été réalisés sur des bannières ${ }^{2}$, des broderies ${ }^{3}$, une collection de drapeaux ${ }^{4}$, un linceul avec portrait du Fayoum ${ }^{5}$, ou encore sur des textiles islamiques ${ }^{6}$. Une $\alpha$-amylase avait été utilisée car il s'agissait d'éliminer une colle d'amidon. Ces traitements avaient été appliqués localement, en bain, sous forme de gel ou de cataplasme ${ }^{7}$. Le cas de la tapisserie était différent car elle était totalement imprégnée et seul un traitement par immersion en bain pouvait être envisagé.

L'enzyme est un catalyseur de réaction chimique. Elle favorise l'hydrolyse d'une substance et est d'autant plus active qu'elle est spécifique au substrat dans les conditions de température et de $\mathrm{pH}$ favorables à son action. Pour éliminer une colle de pâte, on cherche à agir sur l'amidon. L'a-amylase hydrolyse l'amidon ${ }^{8}$ et la dissolution de son hydrolysât entraîne aussi la dissolution de la colle animale. Il faut choisir une enzyme purifiée $^{9}$, ayant une forte activité ${ }^{10}$, afin d'éviter la présence de contaminants comme une protéase (ciblant les protéines des soies et des laines) ou une cellulase (ciblant la cellulose des fils de coton ou de lin) qui risqueraient de causer des dommages irréversibles sur le textile. Une autre difficulté, dans le cas de la tapisserie, portait sur le fait que l'action de l' $\alpha$-amylase était inhibée en présence de métaux. Les analyses de prélèvements des filés métalliques, réalisées par Dominique de Reyer au LRMH, ont conclu, pour la majorité des fils, à un plaquage d'or sur lame d'argent obtenu par laminage, avec une matrice qui est un alliage d'argent et de cuivre ${ }^{11}$. On trouve également un filé d'argent sur les grotesques et dans le liseré des bordures décoratives. La présence de chlore et de soufre indique l'oxydation du métal. La couche d'or est altérée et lacunaire. Ce constat conduisait à s'interroger sur la faisabilité d'un traitement. Une phase d'essai fut alors décidée. Ces tests, ainsi que le reste des opérations présentées ici, ont eu lieu dans l'atelier textile du C2RMF (pavillon de Flore), permettant ainsi de travailler dans les meilleures conditions ${ }^{12}$.

Les premiers tests, réalisés en collaboration avec Anne Rinuy, ingénieur-chimiste, ancien conservateur au laboratoire des Musées d'art et d'histoire de Genève, furent effectués sur des fils de chaque type présents sur la tapisserie, prélevés sur le revers ${ }^{13}$, afin d'observer leur réaction sous diverses conditions de traitement et de déterminer la concentration d'enzyme nécessaire, la température, le $\mathrm{pH}$, la nature de la solution tampon, et le mode opératoire le plus adapté.

\section{Concentration de l' $\alpha$-amylase}

La concentration habituellement employée est de $0,5 \mathrm{mg}$ pour $10 \mathrm{ml}$ de solution ${ }^{14}$. Dans le cas de cette étude, la quantité a été doublée car il s'agissait d'un épais badigeon de colle qui avait pénétré au cœur des fibres et imprégné toute la tapisserie. Pour que l'a-amylase agisse sur la colle, elle doit être dans un milieu liquide favorable. 


\section{Choix de la solution tampon}

Le tampon phosphate avec un pH égal à 6,9 est optimal pour l'activité d'a-amylase. La concentration généralement utilisée varie de 0,1 à $0,3 \mathrm{M}$, mais dans le cas de la tapisserie, on augmente la concentration à $0,5 \mathrm{M}^{15}$, compte tenu de la quantité importante de produits oxydés et acides provenant de la colle de pâte. Il est préparé en solution d'eau déminéralisée. La solution ainsi tamponnée régulera les chutes de $\mathrm{pH}$ lors de la mise en bain du textile. Il semblerait que le tampon phosphate puisse faciliter le mouillage, donc, par extension, favorise le nettoyage du textile.

\section{Température et durée}

La température optimale pour l'activité de l'enzyme est de $37^{\circ} \mathrm{C}$, mais les premiers essais sur fils ont montré un important dégorgement de certains fils de laine et de soie ${ }^{16}$. Une seconde série de tests, réalisée avec une température abaissée à 25-30 ${ }^{\circ} \mathrm{C}$, a montré que l'activité de l'enzyme n'est pas atténuée ${ }^{17}$ et les dégorgements moindres. La durée maximale d'un traitement enzymatique est de 1 h30 ; on a limité la durée du traitement à 30 minutes pour les tests sur fils à cause de leur aspect cassant.

Cette première série de tests montre que certaines soies rouges originales dégorgent légèrement, ce phénomène courant restant contrôlable ${ }^{18}$. Le comportement des fils durant le traitement est satisfaisant et la structure des fils reste stable. Les observations sous binoculaire après traitement révèlent que les fils de laine et de soie, libérés de leur gangue de colle, recouvrent leur soyeux et leur brillant. Les filés métalliques sont dégagés des produits d'oxydation et recouvrent un aspect brillant et doré ${ }^{19}$. Il a donc été décidé de procéder à un second test, cette fois-ci sur une zone déterminée de la tapisserie, en effectuant le mouillage par la face et en choisissant d'augmenter la durée du traitement à 45 minutes environ afin de prolonger l'action des enzymes.

\section{La mise en œuvre du traitement sur la tapisserie}

L'angle inférieur droit de la tapisserie, sur une surface de $20 \times 27 \mathrm{~cm}$, est choisi pour le test ${ }^{20}$ (fig. 4). La zone est placée dans un bac de lavage adapté à ces dimensions. La solution enzymatique est maintenue à température par bain-marie et confinement de l'espace du bain sous une cloche, surmonté de lampes chauffantes. Les mesures de température et de $\mathrm{pH}$ sont régulièrement prises durant le test. Le traitement se fait en deux bains successifs, chacun de 20 minutes environ. Le renouvellement évite les risques de désactivation de l'enzyme par les produits de décomposition de la colle. Les premiers rinçages se font en solution tamponnée à froid pour éliminer les produits hydrolysés et les enzymes, puis les rinçages suivants se font avec de l'eau déminéralisée. La zone est ensuite séchée. Le résultat du traitement est satisfaisant : la colle a été éliminée et l'aspect jaune qui ternissait le tissage a disparu ; les fils sont beaucoup plus souples et brillants sur le revers de la tapisserie et les couleurs reprennent du contraste et de la vivacité (fig. 5). Il reste néanmoins des traces de colle sur le revers, notamment

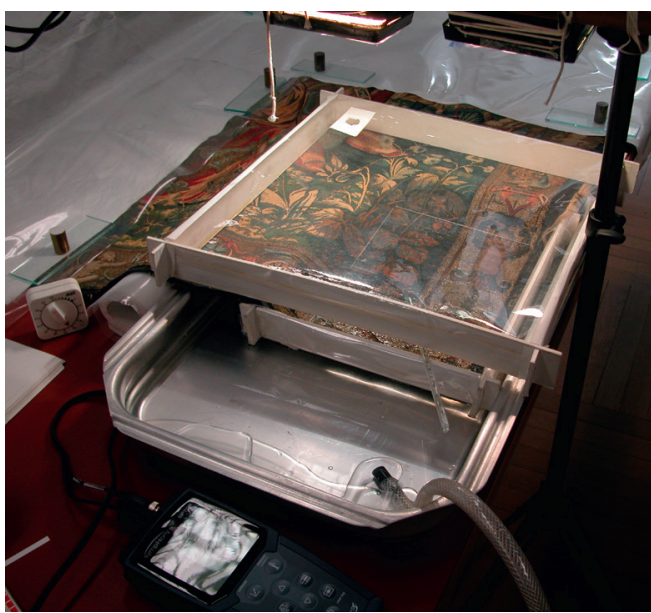

Fig. 4. Test de faisabilité d'un nettoyage enzymatique sur l'angle inférieur droit de la tapisserie. (c) Sylvie Forestier.

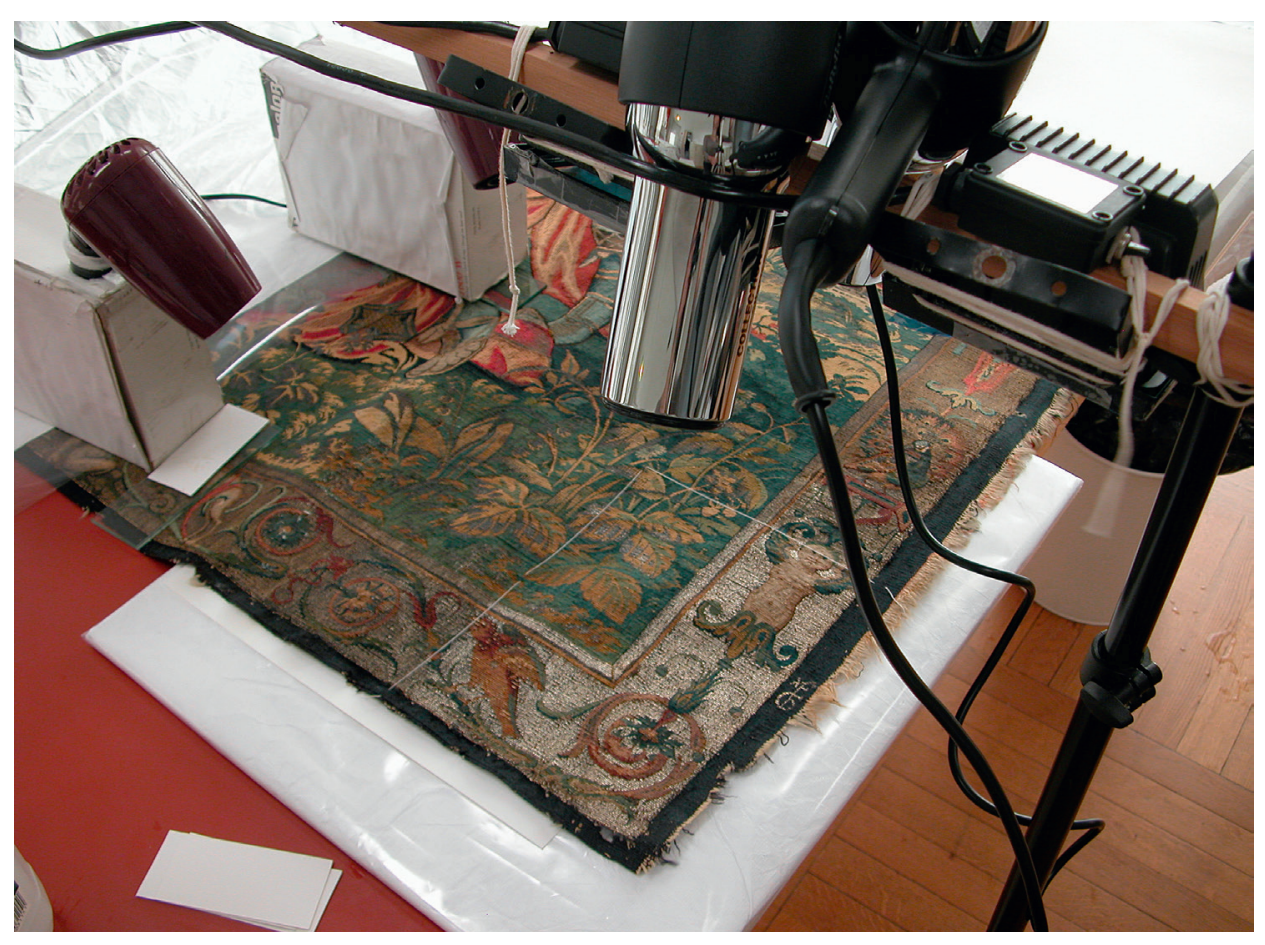

Fig. 5. Résultat du test. (C) Sylvie Forestier. 


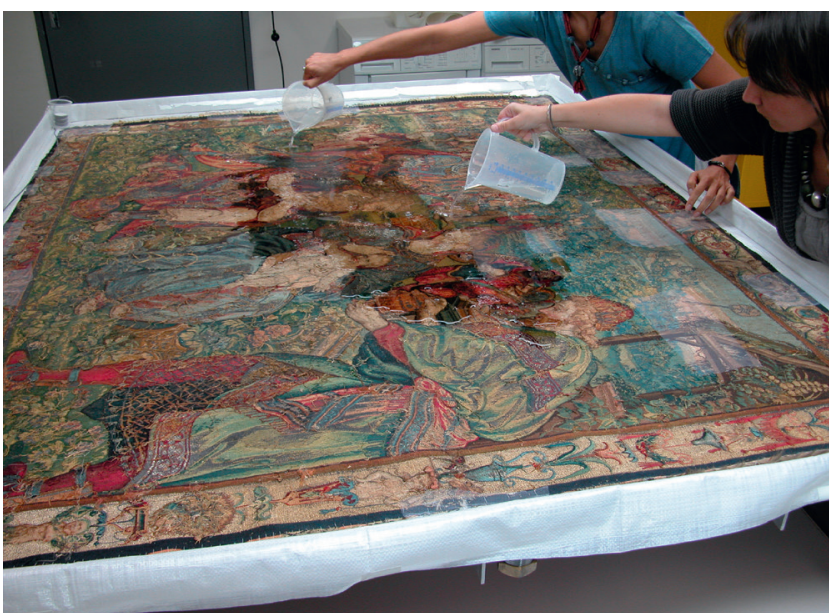

Fig. 6. Mise en bain de la tapisserie posée sur le revers. (c) Sylvie Forestier.

dans les anfractuosités profondes où le mouillage n'était peut-être pas suffisant. Les filés métalliques ont été également débarrassés de ces impuretés et de cet aspect jaune qui les ternissaient. C'est particulièrement marquant dans la bordure où les fils reprennent du brillant et les figures de grotesques sont bien visibles. Les essais de nettoyage ayant été concluants, et après accord de la commission de restauration du Louvre, le traitement de l'ensemble de la tapisserie a été décidé en 2010.

Un bac aux dimensions de la tapisserie $(154 \times 194 \mathrm{~cm})$ a été construit pour cette opération ; il est muni des panneaux chauffants (circuits imprimés sur support de silicone) avec

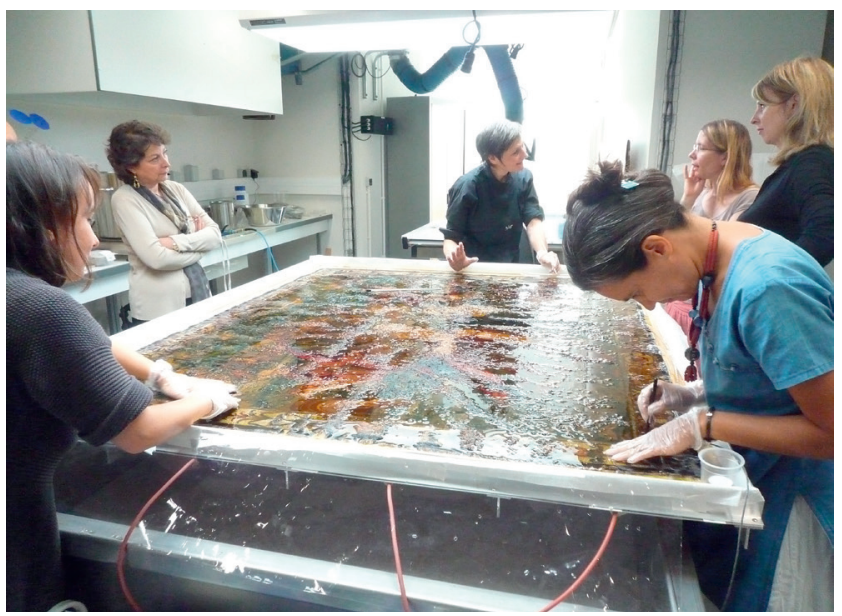

Fig. 7. Traitement en cours sur le revers avec dégagement au pinceau 105

thermostat couplé à une sonde de température qui trempe dans le bain. L'opération a nécessité l'intervention de trois restaurateurs : Sylvie Forestier, Cécilia Aguirre et Thalia Bajon-Bouzid. Le premier bain enzymatique est appliqué sur le revers (fig. 6). Pendant le mouillage, on retire aussi les produits qui enrobent les filés métalliques avec un pinceau souple (fig. 7). L’opération est répétée sur la face. La tapisserie est ensuite rincée, d'abord en bain tamponné à froid puis à l'eau déminéralisée en bain et sur plan incliné. Après chaque rinçage, le liquide est absorbé avec une éponge. La tapisserie est déposée sur la table, puis séchée lentement (alternativement sous plaque de verre et à l'air libre) pour éviter les
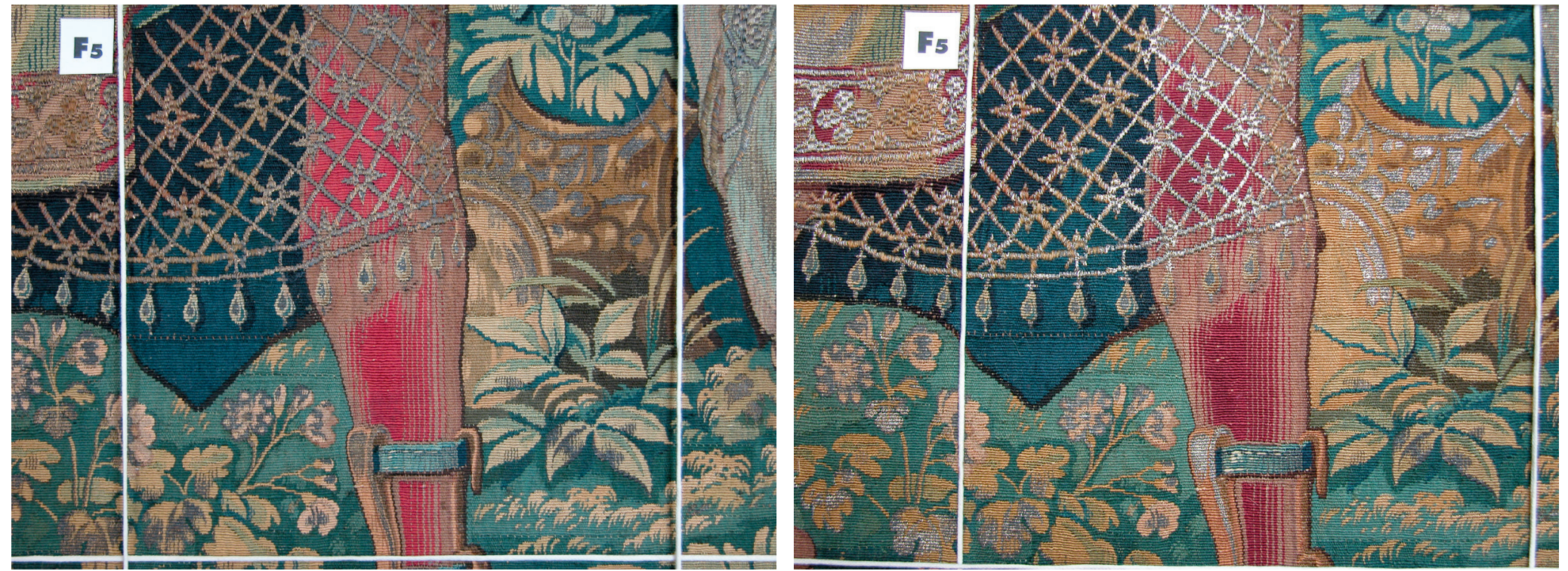

Fig. 8 a et $b$. Détail de la résille du vêtement du mage de gauche avant et après restauration. @ Sylvie Forestier. 
risques de déformation. Des traces de colle résiduelle sur les bords montrent que le badigeon de colle était plus épais sur le périmètre. Devenues pulvérulentes, elles sont éliminées mécaniquement et aspirées simultanément. La tapisserie retrouve une lisibilité qu'elle avait perdue et on redécouvre les jeux de lumière où alternent le mat des laines, les plages brillantes en soie et l'éclat mouvant du métal (fig. 8 a et b).

Après cette opération, la tapisserie a été consolidée de façon classique. Les coutures de relais qui ont rompu sont refermées à l'identique des originales. Les zones fragiles sont consolidées sur des supports en soie ou en lin teints à la couleur (fig. 9). Elles sont principalement situées dans le ciel, sur l'étable et sur les grotesques des bordures hautes et basses. La question de la consolidation des galons bleus des bordures

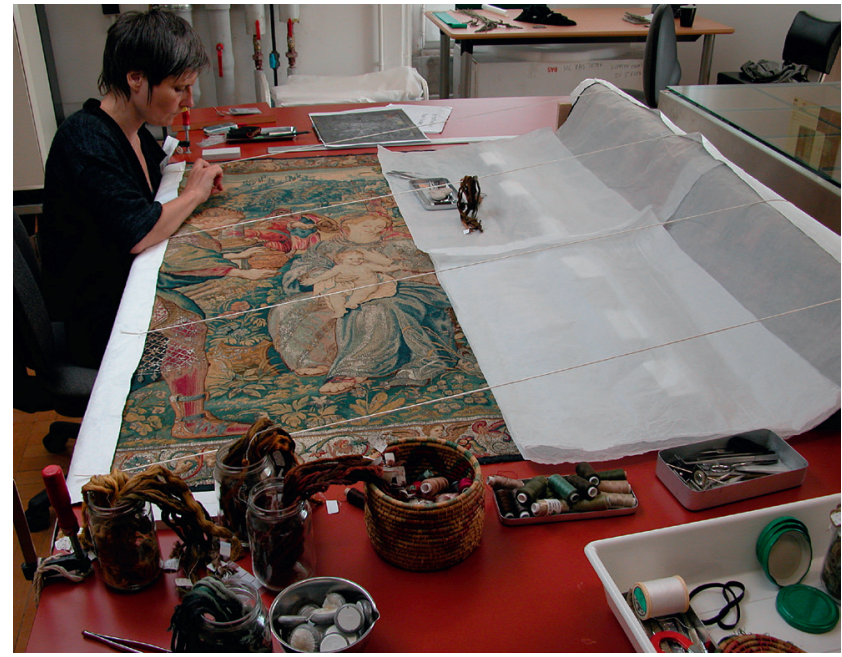

Fig. 9. Tapisserie en cours de consolidation. (c) Sylvie Forestier. s'est posée : lacunaires, notamment aux angles et sur le galon inférieur, les chaînes à nu y sont visibles et gênantes. Il est convenu que les galons seront consolidés sur une toile de lin teinte à la couleur, que les chaînes les plus apparentes seront repliées sur le revers, l'ensemble étant protégé d'une crêpeline de soie teinte. La tapisserie est ensuite doublée et munie d'une bande d'accrochage par velcro. Celle-ci est cousue « hors champ ", au-dessus de la bordure supérieure, pour assurer la conservation de la tapisserie sur le long terme et éviter les problèmes de conditionnement. Cette bande est ensuite recouverte d'une toile de lin teinte dans un ton plus clair que celui des galons (fig. 1).

\section{Conclusion}

Le succès de ce traitement enzymatique, qui semble une première dans le domaine de la tapisserie à filés métalliques, posait la question de la conservation à terme de cette pièce précieuse dont les filés métalliques avaient recouvré leur éclat, afin d'éviter le retour trop rapide de leur oxydation. Il a été décidé de placer la tapisserie dans un caisson climatique, opération qui fut réalisée en 2012 par le restaurateur Patrick Mandron, et la surveillance visuelle de la pièce permet de constater une stabilité satisfaisante de son état. Ajoutons que la redécouverte de la marque Brabant-Bruxelles et du monogramme de l'atelier a relancé sur des bases nouvelles l'étude de la tapisserie : elle a permis de proposer une datation resserrée, vers 1575 , et de faire des hypothèses d'attribution du carton, autour de la personnalité de Michel Coxcie ${ }^{21}$. Le travail de réflexion, de mise en place d'une méthodologie de traitement novateur et sa mise en œuvre ont été, enfin, le résultat d'une démarche collective de partage de compétences particulièrement exemplaire, associant aussi bien des scientifiques du C2RMF, du LRMH et du Musée d'art et d'histoire de Genève, des conservateurs, notamment ceux en charge de la filière Arts décoratifs au C2RMF ${ }^{22}$, et une équipe de restaurateurs. 


\section{Notes}

1. Rapport d'étude $\mathrm{n}^{\circ} 18709$, 18 décembre 2009

2. Shibayama N., Eastop D., 1996.

3. Bott G., 1990.

4. Rinuy A., Fiette A., dans Exp. Genève, 1994, p. 53.

5. Fiette A., 2000

6. Rinuy A., Raster B., 1994.

7. Chapman V., 1986.

8. L'amylase s'attaque aux

macromolécules d'amylose et les morcelle en petites molécules de dextrines, solubles dans l'eau (voir A. Rinuy, Élimination d'adhésifs naturels à l'aide d'enzymes et d'adhésifs synthétiques à l'aide de solvants organiques, formation INP, juillet 2009).

9. $\alpha$-amylase - Type II A $-\mathrm{n}^{\circ} 6380$, du Bacillus spp. environ 1300 unités (SIGMA ALDRICH).

10. Bott G., 1990.

11. LRMH, note T-10-03 (mars 2010) de Dominique de Reyer.

12. Nous remercions Agnès MathieuDaudé, conservatrice alors en charge de la filière Arts décoratifs du C2RMF, de nous avoir ainsi facilité le travail.

13. 20 échantillons de laine,

7 échantillons de fils de soie, 3 échantillons de filés métalliques.

14. Rinuy A., Fiette A., dans Exp.

Genève, 1994, p. 53. ; Fiette A., 2000 ; Rinuy

A., Raster B., 1994.
15. Mélange équimolaire de potassium di-hydrogéno-phosphate $\left(\mathrm{KH}_{2} \mathrm{PO}_{4}\right)$ et de di-potassium hydrogéno-phosphate $\left(\mathrm{K}_{2} \mathrm{HPO}_{4}\right)$ RECTAPUR (VWR).

16. Fil de soie rouge et fil de laine vert (repiquage ponctuel d'une restauration du XIX ${ }^{\mathrm{e}}$ siècle).

17. Un prélèvement de colle mis en bain enzymatique tamponné est dissous au bout de 20 minutes à $28^{\circ} \mathrm{C}$.

18. Par précaution, on retirera les fils de repiquage de laine vert avant le traitement final.

19. Les résultats d'analyses confirment l'amélioration de l'aspect de surface des lames métalliques qui semblent nettoyées. La couche d'or ne montre pas d'altération imputable au traitement (LRMH, note T-11-05 de D. de Reyer, mars 2011).

20. Des essais sur un tissage similaire ont permis de déterminer la quantité d'eau nécessaire au mouillage : soit 11 pour 0,16 $\mathrm{m}^{2}$. La tapisserie étant plus fine, $250 \mathrm{ml}$ de solution sont suffisants pour le mouillage de $540 \mathrm{~cm}^{2}$.

21. Bos A., Forestier S., Mathieu-Daudé A., 2012.

22. Agnès Mathieu-Daudé et Roberta Cortopassi.

\section{Références bibliographiques}

Bos A., Forestier S., Mathieu-Daudé A., «L'Adoration des Mages: une tapisserie de l'atelier de Frans Geubels redécouverte grâce à une restauration inédite ", La Revue des musées de France. Revue du Louvre, 2012, 5, p. 39-48.

Bott G., "Amylase for starch removal from a set of 17 th embroidered panels", The Conservator, 14, 1990, p. 23-29.

Chapman V., "Amylase in a viscous medium textile application", The Conservator, 10 , 1986 , p. 7-11

Fiette A., « Restauration d'un linceul peint redécouvert au Musée d'art et d'histoire de Genève ", Bulletin du CIETA, 77, 2000, p. 15-22.

L'œuvre d'art sous le regard des sciences [Exposition. Genève, Musée d'art et d'histoire, 1994].

Rinuy A., Raster B., «Élimination de restaurations antérieures sur des textiles islamiques de la collection Bouvier ", La conservation des textiles anciens. Actes des journées d'étude de la SFIIC (Angers, 20-22 octobre 1994), [s.1.], 1994 , p. $277-282$

Shibayama N., Eastop D., "Removal of flour paste residues from a painted banner with alpha-amylase", The Conservator, 20 1996 , p. 53-64. 